tives that such a transformation would tend to occur. On the basis of all the evidence presented there cannot be any doubt that the enolization of pyruvic acid represents a logical and simple explanation of the deviation of the oxidation products from mostly acetic and carbonic acids to mostly oxalic and carbonic acids.

From all the above discussion it is clear that alkali performs at least the following functions in the oxidation of acetone:

(I) It gives rise to the reactive enol-isoacetone;

(2) It brings about the enolization of pyruvic acid;

(3) It neutralizes the acids formed and thus interferes with their further oxidation;

(4) It alone determines the velocity of oxidation;

(5) It catalyzes the absorption of atmospheric oxygen.

The point of view developed in this paper concerning the mechanism of the oxidation of acetone is of great interest in the interpretation of the oxidative breakdown of fatty acids. This relation will be discussed in a subsequent paper.

CHICAGO, ILL.

[CONTRIBUTION FROM IHE FORFSt PRODUCTS I,ABORATORY, U. S. DEFT. OF AGRICULTURE.]

\title{
THE ACTION OF ALUMINUM CHLORIDE ON CYMENE.
}

By A. W. SCHORGER.

Received August 28, 1917.

The information available on the action of aluminum chloride on cymene is very meagre. Anschüt ${ }^{1}$ heated cymene with one-third of its weight of aluminum chloride and cursorily remarked that the liquid reaction product contained "betrachtliche Mengen von Toluol." The high boiling portions gave no fractions of uniform boiling point. Boedtke and Halse $^{2}$ heated $90 \mathrm{~g}$. of cymene and $900 \mathrm{~g}$. of benzene with aluminum chloride and obtained $44 \mathrm{~g}$. of toluene and $68 \mathrm{~g}$. of cumene. ${ }^{3}$ The following is a study of this reaction, with determinations of the amount of toluene obtained under different conditions and with the identification of several other components of the reaction.

\section{Experimental Part.}

Cymene.--The cymene used was obtained from "sulfite turpentine."4 The portion distilling between $175^{\circ}$ and $178^{\circ}$ was fractioned repeatedly

${ }^{1}$ Ann., 235, 191 (1886).

2 Bull. soc. chim., 19, 444 (1916).

- After the work on this paper was completed a brief reference to the action of aluminum chloride on cymene was made by Moore and Egloff (Met. Chem. Eng., 17, 66 (r917)). They obtained but $14.3 \%$ toluene with small amounts of benzene and xylene.

Turpentine recovered during the manuiacture of puip from resinous wood by the sulfite process. 
over metallic sodium, but an oil with a constant boiling point could not be obtained. On shaking the distillate with concentrated sulfuric acid the acid layer was colored yellow, while with pure cymene no coloration should be observed. The oil was shaken repeatedly with fresh quantities of the concentrated acid, washed thoroughly with distilled water and dried. After digesting at the boiling temperature with metallic sodium for several hours the oil was fractioned; using a $30 \mathrm{~cm}$. Hempel column filled with glass beads. The nature of the impurity present was not determined, but is probably a terpene. Dilute oxidizing agents such as Beckmann's reagent and dilute potassium permanganate can also be advantageously employed on the crude cymene fraction before the acid treatment. ${ }^{1}$

The cymene purified as above had a pleasing aromatic odor, showed no coloration with concentrated sulfuric acid, and was not attacked by Beckmann's reagent in the cold. It distilled almost entirely between $176^{\circ}$ and $176.6^{\circ}$. The boiling point was corrected for atmospheric pressure by means of the factor $0.057 .{ }^{2}$ The cymene had the following properties: optically inactive; sp. gr. $20^{\circ} / 15^{\circ}, 0.8575 ; n^{20}, \mathrm{I} .4908$; molecular refraction found, $M=45.29$; calculated, $M=44.85$. There is considerable variation in the properties of cymene reported in the literature, ${ }^{3}$ the boiling points varying from $17 \mathrm{I} .5^{\circ}$ to $179.5^{\circ}$, although $175^{\circ}$ to $176^{\circ}$ is generally accepted as the more correct.

The identification of the cymene was further checked by preparation of the thioamide, m. p. I $14^{\circ}$, and by oxidation to p-oxyisopropylbenzoic acid, m. p. $155^{\circ}$.

In Table I are given the results of heating cymene with aluminum chloride at different temperatures. In each experiment $200 \mathrm{~g}$. of cymene were heated with $50 \mathrm{~g}$. of aluminum chloride, using a reflux condenser. The residual oil was recovered by addition of water, and caustic soda solution, dried with anhydrous sodium sulfate and distilled from a Ladenburg flask.

TABLE I.

Effect of temperature and time.

\begin{tabular}{|c|c|c|c|c|}
\hline Temperature of bath & $\begin{array}{c}\text { Expt. } 1 . \\
60^{\circ}\end{array}$ & $\begin{array}{c}\text { Expt. } 2 . \\
98^{\circ}\end{array}$ & $\begin{array}{c}\text { Expt. } 3 . \\
125^{\circ}\end{array}$ & $\begin{array}{c}\text { Expt. } 4 . \\
\text { I5 }\end{array}$ \\
\hline Time of heating in hours...... & 32 & 8 & 2.5 & 3 \\
\hline Gas evolved in cc........... & . & . & 2470 & 5480 \\
\hline Oil recovered in $\mathrm{g} . \ldots \ldots \ldots \ldots$ & I $9 \mathrm{I} .7$ & 190.9 & 186.0 & 177.8 \\
\hline
\end{tabular}

${ }^{1}$ A similar difficulty was experienced by Bogert and Tuttle (Thrs JournaL, 38 , I 352 (I916)). Inresponse to an inquiry Dr. Bogert kindly informed the author that the cymene used in his experiments was obtained from sulfite turpentine.

${ }^{2}$ Kahlbaum, $Z$. physik. Chem., I3, I4 (I894); 26, 577 (I898).

3 Semmler, "Die Aetherischen Oele," IV, ig. 


\begin{tabular}{|c|c|c|c|c|}
\hline \multirow[b]{2}{*}{ Boiling point of fractions. } & \multicolumn{4}{|c|}{ Distillate. } \\
\hline & $\%$ & $\%$. & $\%$. & $\overline{\%}$. \\
\hline$\ldots \ldots \ldots \ldots \ldots \ldots$ & 6.35 & 12.87 & I 3.15 & 22.50 \\
\hline $145^{-160^{\circ}} \ldots$ & 16.43 & 9.10 & 14.85 & 8.66 \\
\hline $160-170^{\circ} .$. & $4 \cdot 52$ & 7.05 & 5.88 & 7.45 \\
\hline I $70-180^{\circ} \ldots$ & 19.30 & $2 I .45$ & 14.65 & 10.00 \\
\hline $180-190^{\circ}$. & 26.38 & 20.88 & I 7.98 & $\mathrm{I}_{4} \cdot 20$ \\
\hline $190-200^{\circ} \ldots \ldots \ldots \ldots \ldots \ldots$ & 7.75 & 8.12 & $7 \cdot 20$ & 6.38 \\
\hline $200-225^{\circ} \ldots \ldots \ldots \ldots \ldots \ldots$ & I I .OO & II .27 & I0.93 & 9.25 \\
\hline Residue................ & 3.60 & 4.05 & 6.45 & 10.25 \\
\hline Total loss. . . . . . . . . . . . . & 4.67 & $5.2 \mathrm{I}$ & $8.9 \mathrm{I}$ & II 3 I \\
\hline
\end{tabular}

The gas evolved was passed through bromine water, but only a trace of an oily bromide separated. Heise and Töhl ${ }^{1}$ found on heating isopropyl benzene with aluminum chloride that the gas given off was almost entirely propane. Since toluene is the chief hydrocarbon formed when cymene is employed, it is probable that propane is the main constituent of the gas formed in the above experiments.

As will be shown later, fraction $200-225^{\circ}$ contains isopropyl cymene. Heise and Töh $1^{2}$ found that low temperatures were favorable for the transfer of the propyl radicle to other molecules. From the data in Table I the temperature does not appear to have a marked effect since the fraction with boiling points $200-225^{\circ}$ remains practically constant, while the amount of toluene increases with rise of temperature.

Several experiments were made using metallic aluminum with mercuric chloride, metallic aluminum with dry hydrogen chloride gas, zinc chloride, and freshly prepared anhydrous ferric chloride. When cymene was allowed to fall upon fused zinc chloride, large amounts of tar and little distillate were obtained. In one case where $2 \mathrm{~g}$. of aluminum powder and $30 \mathrm{~g}$. of mercuric chloride were heated with the cymene in a flask with a reflux condenser for 2.5 hours, fractionation gave $35.6 \%$ of oil distilling below $160^{\circ}$. The mixture should be gently heated to start the reaction as it progresses with considerable violence. The results in all cases were poor compared with those obtained with added aluminum chloride.

In the following experiments $200 \mathrm{~g}$. of cymene were heated with $50 \mathrm{~g}$. of aluminum chloride in a Kjeldahl flask with a Bunsen burner, different gases being passed through the liquid on heating. The cork stopper contained a tube extending to the bottom of the flask, through which the gas was passed in, and a $30 \mathrm{~cm}$. Hempel column containing glass beads, and provided with a thermometer and condenser. The gas, washed with concentrated sulfuric acid, was passed through at the rate of $\mathrm{I}$ to 2 bubbles per second, and the heating was so regulated that the distillate passed

$1 A n n ., 270,161$ (I 892$)$.

2 Ibid., 270, i63 (1892). 
over at the rate of $I$ to 2 drops per second. When the temperature of the distillate reached $120^{\circ}$ the operation was discontinued. The percentages obtained by fractionation of the distillate are based on the cymene.

TABLE II.

Effect of gas on distillate.

\begin{tabular}{|c|c|c|c|c|c|c|}
\hline \multirow[b]{2}{*}{ Expt. No. } & \multirow[b]{2}{*}{ Gas used. } & \multirow[b]{2}{*}{$\begin{array}{l}\text { Total dis- } \\
\text { tillate, } 8 .\end{array}$} & \multicolumn{4}{|c|}{ Fractionation of distillate. } \\
\hline & & & $\begin{array}{c}80-105^{\circ} \\
\%\end{array}$ & $\begin{array}{l}105-117^{\circ} \\
\% .\end{array}$ & $\begin{array}{c}\text { Residue. } \\
\% .\end{array}$ & $\begin{array}{l}\text { Ioss. } \\
\% .\end{array}$ \\
\hline $14 \ldots$ & $\mathrm{HCl}$ & 102.7 & 12.27 & 26.85 & 5.80 & 6.43 \\
\hline $16 \ldots$ & $\mathrm{CO}_{2}$ & 105.9 & 13.60 & 27.50 & 6.55 & $5 \cdot 30$ \\
\hline$x 7 \ldots \ldots \ldots \ldots \ldots$ & Air & $98 . I$ & 12.68 & 23.25 & 12. 10 & I.03 \\
\hline
\end{tabular}

The results given in Table II show that the action of the gas is largely mechanical. Hydrochloric acid gas is invariably used in similar reactions, although carbon dioxide appears to act equally as well. The slightly lower yield of toluene (b. p. $105^{-11} 7^{\circ}$ ) when air is used is not surprising, since Friedel and Crafts ${ }^{1}$ found that some phenol was formed from benzol under similar conditions. The high losses are due to the propane, hydrochloric acid, etc., absorbed by the well cooled distillate.

The action of varying amounts of aluminum chloride was examined under the same conditions as prevailed in the experiments above. The sample consisted of $200 \mathrm{~g}$. of cymene and hydrochloric acid gas was bubbled through during heating.

TABLE III.

Effect of varying amounts of aluminum chloride.

\begin{tabular}{|c|c|c|c|c|c|c|c|}
\hline \multirow{2}{*}{ Expt. No. } & \multirow{2}{*}{\multicolumn{2}{|c|}{$\mathrm{AlCl}_{3}$ used. }} & \multirow[b]{2}{*}{$\begin{array}{l}\text { Total dis- } \\
\text { tillate, } \mathrm{g} .\end{array}$} & \multicolumn{4}{|c|}{ Precipitation of distillate. } \\
\hline & & & & $80-105^{\circ}$. & $105-117^{\circ}$. & Residue. & $\begin{array}{c}\text { Loss. } \\
\% \text {. }\end{array}$ \\
\hline & 100 & 50 & 97.9 & 22.8 & 20.25 & 3.10 & 2.80 \\
\hline $15 \ldots \ldots \ldots$ & $5^{\circ}$ & 25 & II 9.0 & I 3.85 & 28.20 & 9.15 & 8.30 \\
\hline $20 \ldots \ldots \ldots$ & 30 & 15 & 103.5 & I I. 85 & 30.75 & 4.05 & 5.10 \\
\hline $22 \ldots \ldots \ldots$ & 20 & 10 & 133.0 & 10.00 & $24 \cdot 38$ & $25 \cdot 40$ & 6.72 \\
\hline
\end{tabular}

In Expt. 22 the total distillate represents the product passing over up to a temperature of $140^{\circ}$. After additional fractionation with a Hempel column, the following results were obtained:

\begin{tabular}{|c|c|c|c|}
\hline & B. p. & G. & $\%$ \\
\hline Benzene. . . . . . . . . . & $80-95^{\circ}$ & 4.0 & 2.0 \\
\hline Toluene.... & $95^{-120^{\circ}}$ & 84.0 & 42.0 \\
\hline Xylene & $120-145^{\circ}$ & 14.4 & $7 \cdot 3$ \\
\hline
\end{tabular}

The data shows that the larger the amount of catalyst present the greater the amount of benzene formed at the expense of the toluene.

\section{Identification of Hydrocarbons Formed.}

In the identification of the various products formed, the fractions obtained from the above experiments, representing about 1.5 kilos of cymene, were employed.

1 Ann. chim. phys., [6] 14, 435. 
Diisopropyl--Only a few drops of liquid distilling below $80^{\circ}$ were obtained in the course of this work; however, Dr. B. T. Brooks, ${ }^{1}$ who has carried out the reaction on a large scale, isolated diisopropyl. The fraction boiling below $80^{\circ}$ contained $50 \%$ benzene, $42 \%$ diisopropyl, and $8 \%$ lighter products, probably pentane, etc. Ten liters of the fraction below $80^{\circ}$ yielded, after removing the benzene by nitration and distillation, 4.2 liters of diisopropyl, boiling point $56-58^{\circ}$.

Benzene.-The fraction b. p. $80-90^{\circ}$ was nitrated with fuming nitric acid and concentrated sulfuric acid; the dinitrobenzene recrystallized from dilute alcohol melted at $90^{\circ}$.

Toluene. - The toluene fraction distilled almost entirely between ro9I $2^{\circ}$. From this fraction dinitrotoluene, m. p. $70^{\circ}$, was prepared.

$m$-Xylene. -The fraction b. p. $137-142^{\circ}$ was nitrated in the ordinary way; short, slender needles of trinitro- $m$-xylene from alcohol, m. p. $18 \mathrm{I}^{\circ}$. It is very probable that some $p$-xylene was also present. Anschütz ${ }^{2}$ obtained both $m$ - and $p$-xylene from toluene and aluminum chloride.

From theoretical considerations it would seem that cumene would be one of the products formed. The fractions b. p. $150-160^{\circ}$ and $160-170^{\circ}$ were sulfonated and the barium salts subjected to fractional crystallization. Thioamides were prepared from the various fractions. These were oils that hardened on long standing and could be crystallized from water. The crystalline form of the amides varied greatly and melted from $67-70^{\circ}$. In one case an amide that first crystallized in thick rectangular prisms, gave long needles on recrystallization. As a general rule bayonet-shaped needles, m. p. $60-70^{\circ}$, were obtained. There was insufficient material available to complete the identification.

Methyldiisopropylbenzene. - The higher boiling fractions distilled mainly between $205^{\circ}$ and $225^{\circ}$ although the residue boiled as high as $325^{\circ}$, giving oils with a blue floruescence.

Repeated fractionation failed to give a constant boiling product, although the fraction b. p. $215^{-2} 18^{\circ}$ was considerably the largest of the

${ }^{1}$ Dr. Brooks also found that the yield of toluene is greatest when the light low boiling reaction products are permitted to distil from the reaction vessel as fast as formed; also that cymene is very much more easily decomposed by the aluminum chloride than xylene or solvent naphtha. While with $7 \% \mathrm{AlCl}_{3}$ cymene yields $40 \%$ toluene in about 2.5 hours, solvent naphtha yields only 22 to $24 \%$ in twenty hours. With stills of 100 gallons or more it is advisable to use a stirring device. Although diisopropyl was isolated from the fraction below $80^{\circ}$ there was no indication of the presence of any so-called gasoline hydrocarbons in the carefully rectified toluene fraction. In a test run employing solvent naphtha the crude benzene-toluene mixture was rectified through a small column still obtaining a product $95 \%$, of which boiled within a range of $0.6^{\circ}$. A sample of this toluene was also nitrated in the usual way obtaining trinitrotoluene melting at $79.5^{\circ}$. The present high cost of aluminum chloride is the chief factor against the commercial application of the process.

2Ann., 235, I79 (1886). 
three-degree fractions. The fraction b. p. $215^{-21} 8^{\circ}$ had the following properties: $\mathrm{d}_{20^{\circ}}, 0.8668 ; n_{\mathrm{D}}^{20}, \mathrm{x} .4950$; molecular refraction calculated for $\mathrm{CH}_{3} \cdot \mathrm{C}_{6} \mathrm{H}_{3} .\left(\mathrm{C}_{3} \mathrm{H}_{7}\right)_{2}: \mathrm{M}=59.28$; found: $\mathrm{M}=5^{8} .66$. The following ultimate analyses agree well for methyldiisopropylbenzol:

I. $0.1140 \mathrm{~g}$. oil gave $0.3694 \mathrm{~g} . \mathrm{CO}_{2}$ and $0.1 \mathrm{I} 43 \mathrm{~g} . \mathrm{H}_{2} \mathrm{O}$.

II. $0.2 \mathrm{I} 33 \mathrm{~g}$. oil gave $0.6924 \mathrm{~g} . \mathrm{CO}_{2}$ and $0.2 \mathrm{I} 2 \mathrm{I} \mathrm{g} . \mathrm{H}_{2} \mathrm{O}$.

Calc. for $\mathrm{CH}_{3} \cdot \mathrm{C}_{6} \mathrm{H}_{3} \cdot\left(\mathrm{C}_{3} \mathrm{H}_{7}\right)_{2}: \mathrm{C}, 88.54 ; \mathrm{H}, \mathrm{II} .46$. Found: C, $88.38,88.53 ; \mathrm{H}$, II.24, III.I 5 .

Eight grams of the oil were oxidized by heating with $300 \mathrm{~g}$. of $\mathrm{HNO}_{3}$, sp. gr. I.I5, for 8 hours, using a reflux condenser. On cooling, an acid separated in crusts and on evaporation of the mother liquor further portions of the acid were recovered. The acid was purified by prolonged extraction with chloroform in a Soxhlet apparatus. It was soluble to the extent of I part in 312 of water at $95^{\circ}$, separating in the form of microcrystalline needles. It was readily soluble in alcohol, less so in acetone, and very sparingly soluble in chloroform and petroleum ether.

The purified acid proved to be I-methylisophthalic acid $(3,5)$.

On titration with alkali the following results were obtained:

$0.2310 \mathrm{~g}$. of the acid required $25.77 \mathrm{cc}$. of o. I $N \mathrm{NaOH}$.

0.23 I g. of $\mathrm{CH}_{3} \cdot \mathrm{C}_{6} \mathrm{H}_{3}$. $(\mathrm{COOH})_{2}$ requires $25.66 \mathrm{cc}$. o. I $N \mathrm{NaOH}$.

The following ultimate analysis was made:

$0.1665 \mathrm{~g}$. of the acid gave $0.3642 \mathrm{~g}$. of $\mathrm{CO}_{2}$ and $0.0670 \mathrm{~g}$. of $\mathrm{H}_{2} \mathrm{O}$.

Calc. for $\mathrm{CH}_{3} . \mathrm{C}_{6} \mathrm{H}_{3} .(\mathrm{COOH})_{2}: \mathrm{C}, 59.96 ; \mathrm{H}, 4.49$. Found: $59.66,4.30$.

Regenerated from the dimethyl ester, the acid melted at $298^{\circ}$. The sublimed acid melted at the same temperature, showing that anhydride formation had not occurred. On the other hand, when condensed with resorcinol, by means of sulfuric acid, the resulting product showed a perceptible fluorescein reaction which is considered proof of the presence of two adjacent carboxyl groups.

The dimethyl ester not previously known was prepared from phosphorus pentachloride and methyl alcohol in the usual way. Recrystallized from dilute alcohol, it is obtained as a felt-like mass of fine needles melting at $98^{\circ}$.

The ester analyzed as follows:

I. $0.1 \mathrm{I} 8 \mathrm{I} \mathrm{g}$. of ester gave $0.274^{8} \mathrm{~g} . \mathrm{CO}_{2}$ and $0.0639 \mathrm{~g} . \mathrm{H}_{2} \mathrm{O}$.

II. $0.1826 \mathrm{~g}$. of ester gave $0.4232 \mathrm{~g} \cdot \mathrm{CO}_{2}$ and $0.0958 \mathrm{~g} . \mathrm{H}_{2} \mathrm{O}$.

Calc. for $\mathrm{CH}_{3} . \mathrm{C}_{6} \mathrm{H}_{3} .\left(\mathrm{COOCH}_{3}\right)_{2}: \mathrm{C}, 63.42 ; \mathrm{H}, 5.82 ; \mathrm{O}, 30.76$. Found: $\mathrm{C}, 63.46$, 63.2I, H, 6.06, 5.88; O, 30.49, 30.9I.

Five grams of the acid with $5.5 \mathrm{~g}$. of sodium hydroxide and $15 \mathrm{~g}$. of potassium permanganate in $700 \mathrm{cc}$. of water were heated on the steam bath in a loosely stoppered flask for $48 \mathrm{hrs}$. The oxidation takes place smoothly and nearly quantitatively to symmetrical benzene tricarboxylic acid. The slight excess of potassium permanganate was destroyed with a few drops of alcohol. The filtrate, after removal of the manganese 
dioxide, was concentrated to about $75 \mathrm{cc}$. and the acid precipitated with hydrochloric acid. Recrystallized from hot water, the acid was obtained as short, fine needles that melted indefinitely above $300^{\circ}$. When allowed to crystallize spontaneously from ether, long, slender needles were obtained that melted quite sharply at $360^{\circ}$ by rapid heating. ${ }^{1}$ According to the older results ${ }^{2}$ trimesic acid sublimes above $300^{\circ}$ before its melting point is reached. Pechmann, ${ }^{3}$ using an air bath, obtained the m. p. $345^{-} 35^{\circ}$.

The trimethyl ester melted at $142^{\circ}$. The triethyl ester crystallized from $95 \%$ alcohol in long, slender needles that began to sinter at $127^{\circ}$ and melted at $133^{\circ}$.

The formation of $\mathrm{I}$-methylterephthalic acid $(3,5)$ and its oxidation to (S) trimesic acid shows clearly that the constitution of the hydrocarbon is I-methyl-3,5-diisopropyl benzene. This compound had not been previously prepared. A question might be raised in regard to the groups being $n$-propyl or isopropyl. It should be remembered, however, that the isopropyl group is the more stable form, especially in the presence of aluminum chloride. Isopropylbenzol heated with aluminum chloride gives diisopropylbenzol; ${ }^{4}$ isopropylbenzol was obtained by Gustavson ${ }^{5}$ by heating benzol with either $n$-propyl or isopropyl bromide and aluminum chloride, since $n$-propyl bromide rearranges to the isopropyl bromide in presence of aluminum bromide; ${ }^{6}$ and Jacobsen ${ }^{7}$ obtained $p$-cymene by treating $n$-propyliodide and $p$-bromotoluene with sodium.

The (S)-trimesic acid obtained by crystallization from water gave a strong fluorescein reaction which was not obtained from the acid crystallized sufficiently from ether. The former, however, titrated exactly for a tricarboxylic acid.

0.1505 g. of acid required 21.44 cc. O.I $N \mathrm{NaOH}$.

0.1505 g. of $\mathrm{C}_{6} \mathrm{H}_{3}(\mathrm{COOH})_{3}$ requires 21.49 cc. o.I $N \mathrm{NaOH}$.

From theoretical considerations also, it seemed probable that trimellitic acid would be present. Ten grams of the acid were treated in aqueous solution with the calculated quantity of dry sodium carbonate to form monosodium salt and submitted to fractional crystallization. The diff-

1 For determining high melting points the writer uses a double bath containing a eutectic mixture of potassium nitrate $(54.5 \%)$ and sodium nitrate that begins to melt at about $220^{\circ}$. A coloriess liquid is obtained that does not fume, and is noncorrosive. It is somewhat surprising that Mulliken ("Identification of Organic Compounds," I, 2 I 8 ) recommends a mixture of sulfuric acid and potassium sulfate which is disagreeable to handle.

${ }^{2}$ Fittig, Ann., I4I, I53 (1867); Baeyer, Ber., 19, 2 I86 (I 886).

${ }^{3} A n n ., 264,295$ ( 1891 ).

${ }^{4}$ Uhlhorn, Ber., 23, 3 I42 (I890); Heise and Töhl, Ann., 270, 159 (1892).

5Ber, II, I24I (I878).

${ }^{6}$ Kekulé and Schrötter, Ibid., 12, 2280 (1879).

${ }^{7}$ Ibid., II, 2050 ( 1878 ). 
cultly soluble monosodium salt of trimesic acid ${ }^{1}$ was obtained in the form of shiny, flat needles on slowly cooling the concentrated solution. However, the acid giving the fluorescein reaction could not be satisfactorily identified, owing to its small amount and the difficulty of complete separation from trimesic acid.

The method of formation of I-methyl-3,5-diisopropyl benzene is problematical but probably first takes place by the addition of an isopropyl group to cymene according to (I) or (II).

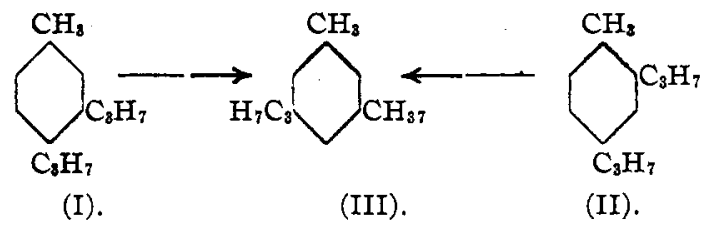

The latter then rearranged to the more stable symmetrical form (III), in the one case involving the migration of an isopropyl group and in the other a methyl group. Preference is given to (I) on account of the evidence of the presence of a small amount of methylphthalic acid and trimellitic acid.

Thioamide of I-Methyl-3,5-diisopropyl Benzene.-The thioamide was prepared by treating the hydrocarbon with an equal volume of chlorosulfonic acid at room temperature, pouring into cold water, extracting with ether, and heating the thiochloride on the steam bath with concentrated ammonia. The resulting amide was obtained as a glassy ambercolored mass, insoluble in water, but readily soluble in alcohol, chloroform, ether and ethyl acetate. After standing exposed to winter temperature for several days the mass became opaque through the formation of small crystals. These were found to be insoluble in petroleum ether, with which the mass was triturated in the cold. The crystals separated by means of the force filter were purified by repeated solution in a minimum amount of chloroform and precipitation with petroleum ether; they melted at $92^{\circ}$. The amide crystallized spontaneously from alcohol in transparent rectangular plates.

The nitrogen was determined by the Kjeldahl method; the sulfur was determined by combustion with sodium peroxide in the bomb of a Parr calorimeter.

I. $0.5247 \mathrm{~g}$. amide gave $0.4875 \mathrm{~g}$. $\mathrm{BaSO}_{4}$.

II. $0.3974 \mathrm{~g}$. amide gave $0.3709 \mathrm{~g}$. $\mathrm{BaSO}_{4}$.

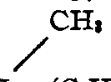

Calc. for $\mathrm{H}_{2} \mathrm{~N} . \mathrm{SO}_{2} . \mathrm{C}_{6} \mathrm{H}_{2}-\left(\mathrm{C}_{3} \mathrm{H}_{7}\right)_{2}: \mathrm{S}, 12.56, \mathrm{~N}, 5.49$. Found: $\mathrm{S}, 12.76,12.4 \mathrm{Y} ; \mathrm{N}$, $5.68,5.66$.

Evidence of the presence of diisopropylbenzol, or dimethylisopropyl-

' Fittig and Furtenbach, Ann., 147, 305 (1868). 
benzol was not obtained. The reaction of aluminum chloride with cymene offers the opportunity for the formation of many compounds that might readily be overlooked when the reaction is carried out on a small scale.

\section{Summary.}

I. By the action of aluminum chloride on cymene there is formed diisopropyl, benzene, toluene, $m$-xylene, and I-methyl-3,5-diisopropylbenzene. The latter compound so far as known has never been previously described.

2. Small amounts of the catalyzer favor the formation of toluene, while the formation of benzene increases with the amount of catalyzer employed.

Madison, Wis.

[CONTRIbUtion FROM the Chemical Laboratory of Harvard University.]

\section{THE ACTION OF PHOSPHORUS TRICHLORIDE ON UNSATURATED KETONES. \\ [PRELIMINARY PAPER.] \\ By Jayas B. CoNant. \\ Received September 27, 1917.}

During the course of some experiments on the action of acid chlorides on $\alpha, \beta$-unsaturated ketones it was discovered that benzalacetophenone in glacial acetic acid solution reacted with phosphorus trichloride. On diluting with water, a substance was precipitated which was found to be a ketonic phosphonic acid. Satisfactory results could only be obtained by the use of glacial acetic acid as the solvent. An attempt to find a similar case in the literature, revealed the fact that Fossick ${ }^{1}$ had studied a somewhat analogous reaction between aldehydes and phosphorus trichloride, but had employed no solvent. The oily addition compounds which he obtained yielded, on treatment with water, oxyphosphonic acids of the type $\mathrm{RCHOHPO} \mathrm{H}_{2}$. Aside from this work and one or two isolated observations, ${ }^{2}$ no investigation has been made of the action of phosphorus trichloride on substances having a carbonyl group, other than acids. A further study was hence undertaken, not only of the action of the reagent on unsaturated ketones, but also of the reaction with various types of aldehydes and ketones when dissolved in glacial acetic acid. The branch of the work dealing with unsaturated ketones has unfortunately been interrupted, so that the following is only an account of the preliminary experiments. It is hoped that this research may be soon continued with a view to determining the mechanism of the reaction and the limits of its applicability.

Three unsaturated ketones were employed in this work: anisalacetophe-

1 Monatsh., 5, 527 (1885); 7, 31 (1887).

${ }^{2}$ Ann., 281, 363; Ber., 18, 899 (I885); 34, 129 I (I901). 